\title{
The Use of 3D Modeling in the Diagnosis of Power Capacitors with Acoustic Emission Method
}

\author{
T. Boczar*, A. BŁachowicz, S. Borucki and D. Zmarzey \\ Faculty of Electrical Engineering, Automatic Control and Computer Science, Opole University of Technology \\ S. Mikołajczyka 5, 45-271 Opole, Poland
}

The article presents the issue modelling the partial discharge phenomenon in engineering and scientific environments using hardware-based computer cluster. The authors present the results of research work on the phenomenon of acoustic emission from partial discharge occurring in power capacitors for power factor correction. The work includes the issues presentation and explanation of solutions enabling to create 3D spatial model of power capacitor. The authors proposed a simplified model of an acoustic test object aimed at improving the process of calculating the results.

PACS: 43.40.Le, 07.05.Tp

\section{Introduction}

One of the most common causes of a breakdown of the power system is a defect of insulation set caused by the aging of the isolation. Insulation sets occurs in all parts of the power system. Accumulation of defects is accompanied by increased frequency of the occurrence of partial discharge (PD), which contributes to accelerate the degradation of the insulating material, especially systems based on paper-oil insulation [1-7].

The article presents the issue modeling the PD phenomenon in engineering and scientific environments using hardware-based computer cluster. The authors present the results of research work on the phenomenon of acoustic emission (AE) from PD occurring in power capacitors for power factor correction. The work includes the issues presentation and explanation of solutions enabling to create 3D spatial model of power capacitor made in Autodesk Inventor environment.

The authors proposed a simplified model of an acoustic test object aimed at improving the process of calculating the results. Designed in the environment to create a spatial objects model has been supplemented by the physical properties in COMSOL Multiphisics computing environment. There have been reports of the solutions of the partial model of power capacitor computing environment with different types of AE signals. The final element of the article is a generalized description of cluster-based computing solutions from Microsoft, namely Windows HPC Server 2008 R2, constructed for the purpose of research on the phenomenon of AE from PD.

\footnotetext{
* corresponding author; e-mail: tboczar@gmail.com
}

\section{Real object, power capacitor for power factory correction}

The virtualized object is capacitor (middle voltage, MV) produced in 1981 by ZWAR Poland with rated power 50 kvar; the acoustic model was moved to a three-dimensional reality with the help of engineering research environments [1, 2].

TABLE I

Basic parameters of rolling capacitor, producer ZWAR Poland, type C9,09/50-1.

\begin{tabular}{c|c}
\hline \hline Producer & ZWAR Poland \\
\hline year & 1981 \\
type & $\mathrm{C} 9,09 / 50-1(01089)$ \\
non-flammable \\
insulation system & $2.06 \mu \mathrm{F}$ \\
capacity & $9.09 \mathrm{kV} / 50 \mathrm{~Hz}$ \\
nominal voltage & $5.5 \mathrm{~A}$ \\
nominal current & $1.95 \mathrm{kvar} / \mathrm{dcm}^{3}$ \\
power density ratio & $50 \mathrm{kvar}$ \\
rated power &
\end{tabular}

The virtualization process presents main elements for the acoustic model. In the next part of this paper there are given details of the materials and dimensions of the individual parts making up the structure. Basic technical parameters of capacitor C9,09/50-1 are summarized in the table below (Table I). Photos of the described capacitor are presented below (Fig. 1).

Internal structure is shown in Fig. 2. It is formed by 32 rollers of the capacitor, that are connected in series and parallel configurations. 

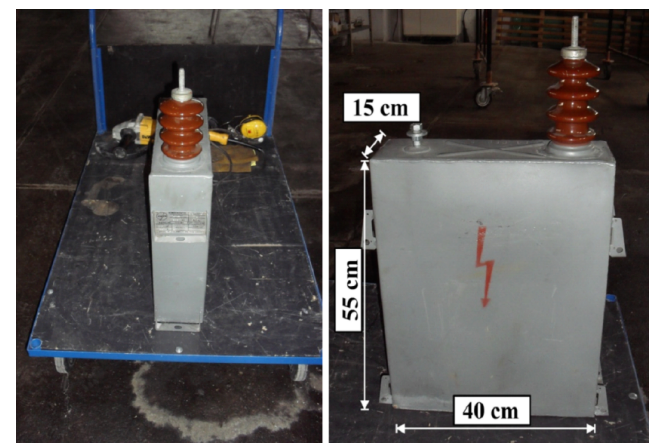

Fig. 1. Views of power capacitor, type C9,09/50-1 [own picture].

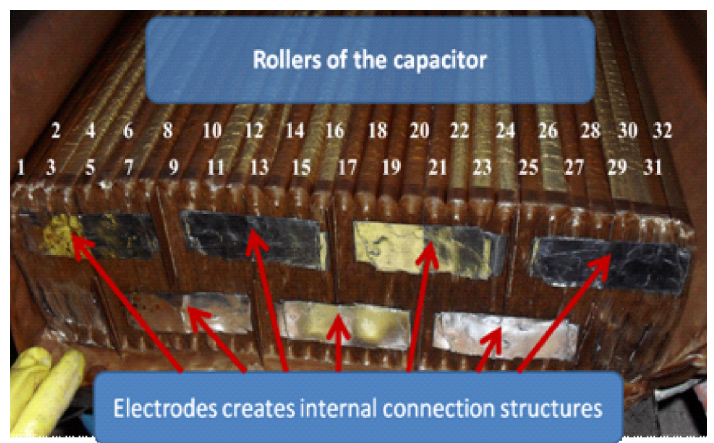

Fig. 2. In the power capacitor type C9,09/50-1 there are located 32 rollers of aluminium-cellulose and polystyrene [own picture].

Rollers are made layer of cellulose (dielectric, insulation system) located between the layer of aluminium electrodes like electric transducers.

\section{Modeling of AE wave from PD in power capacitor $3 \mathrm{D}$ model}

Structure of the model is showed in Fig. 3. It consists of the following elements essential for study of the phenomenon of PD. Defined are the following representing the parts of facilities, such as:

- The layer of air surrounding the case.

- Case made of stainless steel.

- Cellulose between case and interior structure.

- Fluid insulation filling the interior space.

- The electrodes made of aluminium.

- Cellulose — solid insulator.

Each of layers has the parameters that characterize its physical properties. In point of view of created model it has particularly important phenomena such as: acoustic waves refraction, acoustic wave reflection, and acoustic

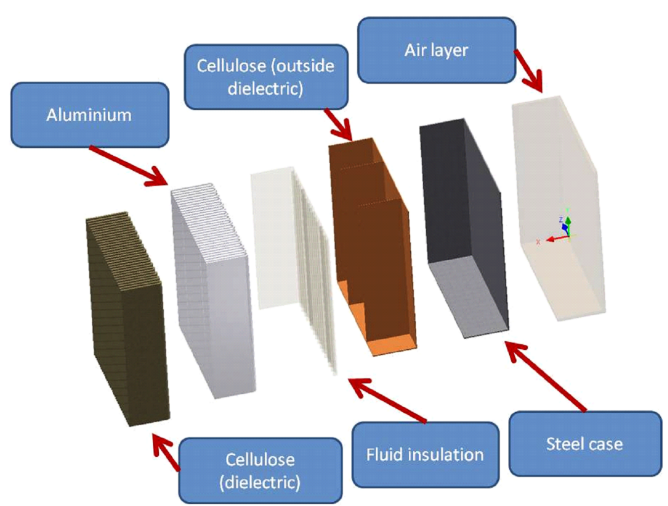

Fig. 3. Model construction [own picture].

wave attenuation. It is an adaptation of model layers that define the physical parameters, allowed to get as close as possible to the actual results of the simulation. It should be noted that the receiving of such effects is extremely difficult, hence the use of a number of improvements $[5-7]$.

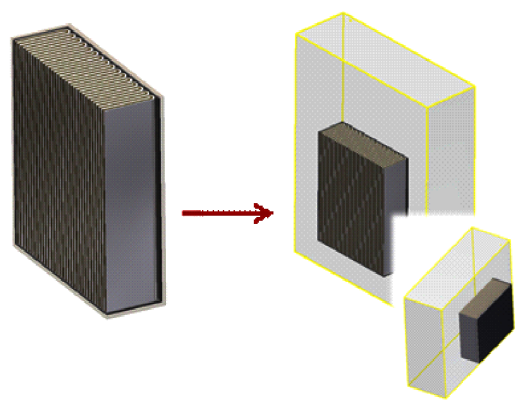

Fig. 4. Symmetry of the model [own picture].

Completed capacitor's model is shown in Fig. 4. The capacitor is divided into symmetrical parts. The complexity of the calculation procedure made the model to be divided into 8 parts of a capacitor. As a result of the simulation model consist of one of 8 parts.

\section{Wave simulation of AE from PD phenomena}

Acoustic wave source is a sphere with a diameter of $5 \mathrm{~mm}$. In research environment Comsol Multiphisics walls of sphere should be defined which emit the acoustic wave. In this case the source of acoustic wave are walls between the capacitor model and sphere. Two parts of sphere (two walls joint sphere and capacitor model) are source of acoustic wave [5].

Model discretization is an obligatory element in the process of generating the result (Fig. 5). In order to establish the number of points, in the computational simulation, the minimum and maximum distance between two next elements should be defined. Selection of these 


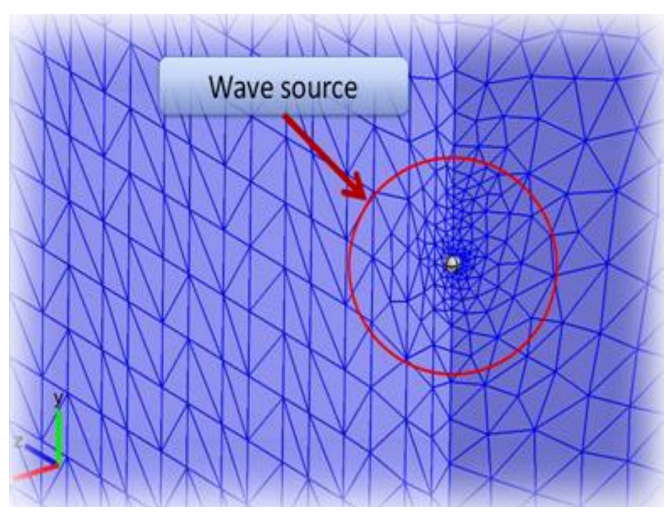

Fig. 5. Wave source localisation.

distances is closely connected with the wavelength of the signal emitted from the source. The process of value choice is presented in Table II.

Distance between two next elements of grid

TABLE II depending on the frequency of the signal.

\begin{tabular}{c|c|c|c|c}
\hline \hline No. & $\begin{array}{c}f[\mathrm{kHz}] \\
\text { (frequency) }\end{array}$ & $\begin{array}{c}T[\mu \mathrm{s}] \\
\text { (wave } \\
\text { period) } \\
T=1 / f\end{array}$ & $\begin{array}{c}\lambda[\mathrm{m}] \\
\text { (wave length) } \\
\lambda=V \times T \\
(V-\text { speed) }\end{array}$ & $\begin{array}{c}d[\mathrm{~mm}] \\
\text { (distance between } \\
\text { two next } \\
\text { elements of grid) }\end{array}$ \\
\hline 1. & 50 & 20 & 0.0278 & $5.56-13.9$ \\
2. & 100 & 10 & 0.0139 & $2.78-6.95$ \\
3. & 200 & 5 & 0.00695 & $1.39-3.475$ \\
4. & 300 & 3.33 & 0.0046287 & $0.92574-2.31435$ \\
5. & 400 & 2.5 & 0.003475 & $0.695-1.7375$ \\
6. & 500 & 2 & 0.00278 & $0.556-1.39$ \\
7. & 600 & 1.66 & 0.0023213 & $0.46426-1.16065$
\end{tabular}

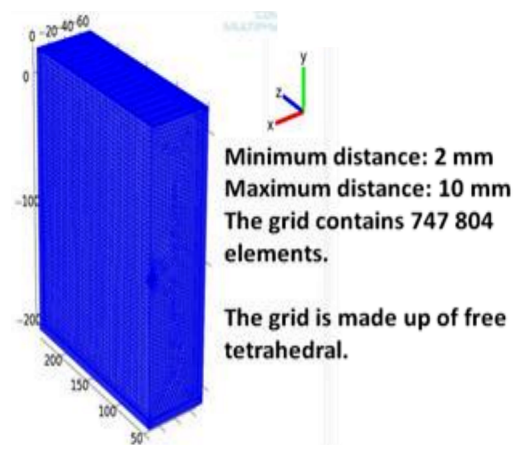

Fig. 6. Discretization of the object.

Simulation parameters:

- Number of vertex: 319 ,

- Number of edges: 8483 ,

- Number of boundary elements: 98854 ,

- Elements: 266732 ,

- Minimum quality: 0.1298,

- Distance (min., max.): $2 \mathrm{~mm}$ to $10 \mathrm{~mm}$,
- Start conditions: $p\left(t_{0}\right)=0$ and $\delta p / \delta t\left(t_{0}\right)=0$,

- Signal frequency (sin): $100 \mathrm{kHz}$,

- Maximum pressure: $1 \mathrm{~Pa}$,

- Simulation time: $100 \mathrm{~ms}$,

- Solution in: $3789 \mathrm{~s}$.

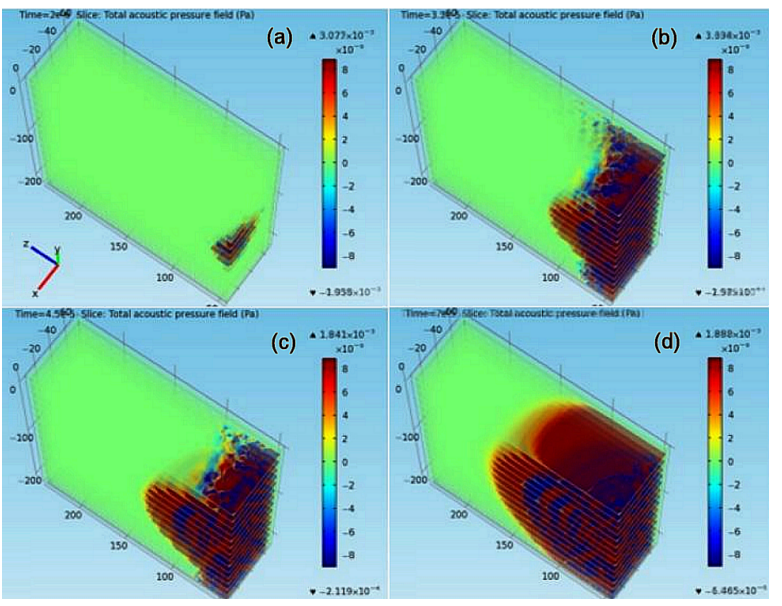

Fig. 7. Time: (a) $2 \times 10^{-6} \mathrm{~s}$, (b) $2.2 \times 10^{-5} \mathrm{~s}$, (c) $4.5 \times$ $10^{-5} \mathrm{~s},(\mathrm{~d}) 7 \times 10^{-5} \mathrm{~s}$.

Figure 7 presents how the acoustic wave propagates through the elements of the structure in creating acoustic model of power capacitor.

\section{Cluster computing structure for simulation process}

For the parallelization of computational processes in COMSOL Multiphisics, it has used technology such as:

- Windows Server 2008,

- High Performance Computing Pack 2008 for Windows Server.

This provided a 6-times faster calculation than normally with one node in cluster.

Units in the network were connected to fast $1 \mathrm{~Gb}$ Ethernet network. With the help of appropriate software package COMSOL Multiphisics makes a connection to each cluster nodes. The master node is configured to simulate this part of the calculation process in parallel mode, where the data to other units has been sent. There were made calculations of certain parts of data. Solutions results went directly into the root node of the cluster. This operation is repeated several times giving parallel the effect of cluster units. 


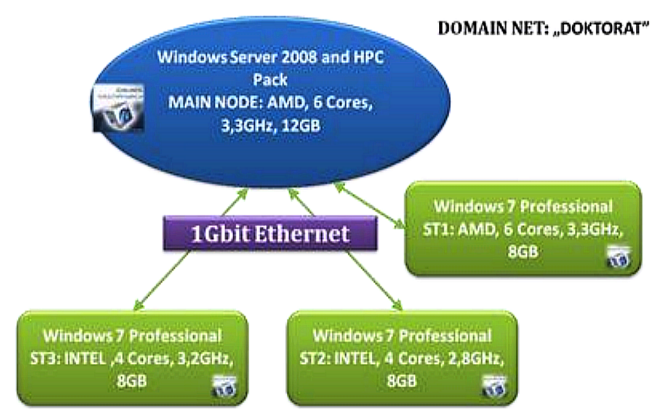

Fig. 8. Cluster computing in a PD researches.

\section{Conclusion}

Researches carried out in the Institute of Electrical Power Engineering are designed to develop methods that allow modelling of the phenomena occurring in the power network devices. Their potential to simulate the processes occurring in the real objects will improve the research process and replace dangerous measurement by the modelling methods. Modelling of physical phenomena using the tools of engineering and research can get more and more close to the actual results. Using the developed numerical tools to predict the state of electrical equipment, the capacity is achieved with a powerful diagnostic potential.

\section{Acknowledgments}

The work was financed with the means from the National Research and Development Center within LIDER program.

\section{References}

[1] B. Gronowski, Ph.D. Thesis, Electrical Faculty AT PW, Warsaw 1989 (in Polish).

[2] J. Skubis, Acoustical Emission for Testing of Insulattors of Power Systems, IPPT PAN, Publish of Opole UT, Opole 1998 (in Polish).

[3] P. Struk, T. Pustelny, K. Gut, K. Golaszewska, E. Kaminska, M. Ekielski, Acta Phys. Pol. A 116, 414 (2009).

[4] J. Ignac-Nowicka, T. Pustelny, Z. Opilski, W. Maciak, W. Jakubik, M. Urbanczyk, Opt. Eng. 42, 2978 (2003).

[5] S.A. Ashraf, B.G. Stewart, C. Zhou, M.J. Jahabar, : Annual Report of Conf. on Electrical Insulation and Dielectric Phenomena, Salalah College of Technology, Salalah (Oman) 2006, p. 203.

[6] A.O. Akumu, F. Adachi, K. Arii, in: IEEE Int. Symp. on Electrical Insulation, Ehime University, Matsuyama 2002, p 331.

[7] S.A. Ashraf, B.G. Stewart, C. Zhou, J. Jahabar, in: 3rd Int. IEEE-GCC Conf., Bahrain, Salalah College of Technology, Salalah (Oman) 2006, p. 291. 